\title{
NIDCAP Partners with Industrial Design: Training for Success
}

\author{
Tybekhan JM 1,2,3, Van der Leek C ${ }^{4}$, Gustin B ${ }^{4}$, Salamon $K^{4}$, \\ von Hauff $P^{5}$ \\ 'Stollery Children's Hospital \\ 2 Dept of Pediatrics, University of Alberta \\ ${ }^{3}$ Edmonton NIDCAP Training Centre Canada (ENTCC) \\ ${ }^{4}$ Dept of Industrial Design, University of Alberta \\ ${ }^{5}$ Academic Technology, Faculty of Medicine and Dentistry, \\ University of Alberta. (All located in Edmonton, Canada)
}

\section{Background}

The NFI's Strategic Plan (2017) includes "Strengthening NIDCAP training processes" and "Expanding NIDCAP education and training resources". ${ }^{1}$ NFI members discussed 'Training Materials and Pathways' at the NIDCAP Trainers Meeting 2019. ${ }^{2}$ However, constraints of time, people-power and resources mean that a logical starting point for the development of enhanced Training Materials has not yet been defined.

Coincidentally, the Edmonton NICU has been exploring the creation of an online educational platform with the Departments of Academic Technology (AT) and Industrial Design (ID) at the University of Alberta (U of A). This platform could host specialized training programs offered in Edmonton - one of these being NIDCAP. ${ }^{3}$

AT and ID at U of A have previously developed educational material for use in clinical settings, e.g. neonatal resuscitation, ${ }^{4}$ electronic portfolios. ${ }^{5}$ Some of this work is distinctly family-focused, e.g. 3-D models of the heart to help families and learners understand the anatomy of congenital cardiac anomalies. ${ }^{6}$ Learning about this work led to the first meeting of our study team. AT faculty and ID students quickly grasped the essence of NIDCAP and three students devoted their final practicum to this project.

\section{Aims/Purpose}

ID brings an interdisciplinary approach to improve the quality of experience and to overcome challenges, using profession-specific analytical methods. The aim was to use the ID perspective to create a model to serve NIDCAP in a contemporary, globalised context. For this first phase of our collaborative project, ID students focused on the educational pathway of NIDCAP Training, i.e. preliminary readings, didactic lecture, individual training, Advanced Practicum of NIDCAP training, and certification.

\section{Relevance to NIDCAP}

NIDCAP is a training program. Augmenting the success of this training will directly impact clinical care and improve the outcomes of hospitalised newborn infants. This project directly addresses some of the NFI's Strategic Goals. ${ }^{1}$

\section{Methods}

DOI: $10.14434 /$ do.v15il.33779

Primary research methods included interviews, and the use of convergent and divergent design thinking, using a 'Double Diamond' diagram (Figure 1). The Double Diamond is a common design model used to showcase different thinking skills throughout a design process. ID students visited the Edmonton NIDCAP Training Centre Canada (ENTCC) to gain an understanding of the NIDCAP Training framework, and the intricate relationship of Trainer and Trainee. They toured the NICU to see 'NIDCAP in Action'. Further insights were obtained through interviews with members of ENTCC and the Edmonton NICU Program. The ID approach of interviews and design-based methodology enabled critical analysis and distillation of the multilayered steps of NIDCAP Training. Creating a series of Spider Diagrams enabled the delineation of areas of intervention and existing relationships within the NIDCAP Training pathway, (Figure 2). This led to a practical, defined starting point for a small change that could have great impact.

\section{FIGURE 1 - A Design Process: Convergent and Divergent Thinking Diamond}

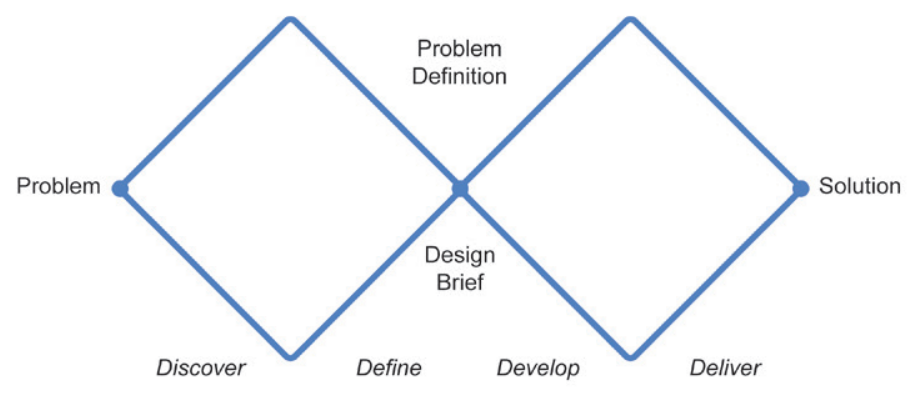

\section{Results/Findings}

The study team agreed early in the process that a functional, on-line learning platform could not be created without this preliminary work. ID methodology led to a practical first step towards enhanced NIDCAP Training: "How can the NIDCAP Observation Sheet be made easier to learn?" The sequential stages that led to this result will be explained during the presentation. The goal was not to change the existing Observation Sheet; making this easier for trainees would be similar to practice exercises for learning the use of a computer keyboard.

\section{Conclusions}

ID methodology applied to the NIDCAP Training Pathway found that the NIDCAP Observation Sheet is a logical first 


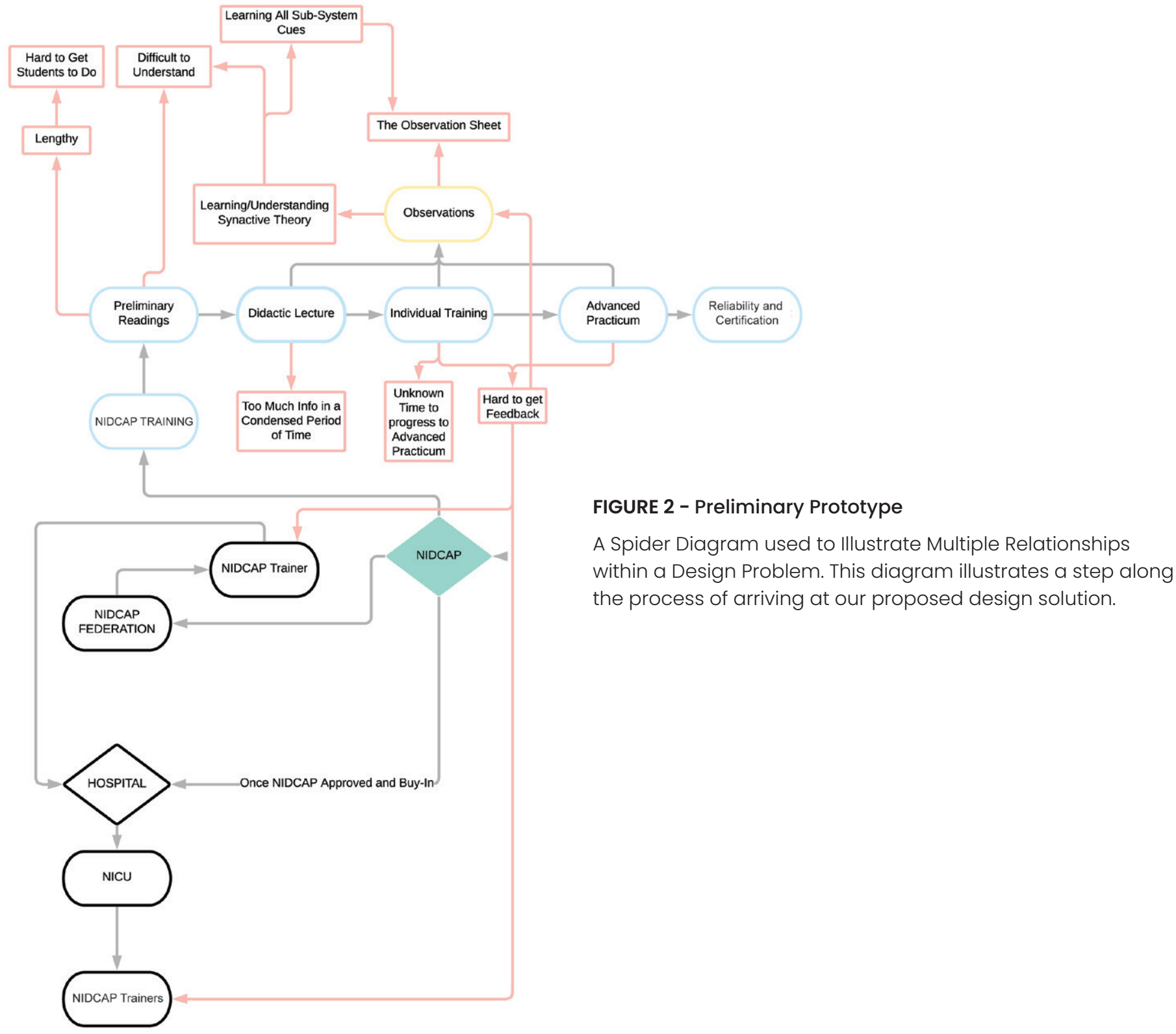

point for adaptation. This conclusion could provide focus for the NFI's Next Steps related to Training Materials and Pathways. Further work should explore such adaptation(s), with respect to the educational experience and success of training. Collaboration with AT, ID and other professions could help accomplish NFI Strategic Goals.

\section{References:}

1. NIDCAP Federation International (NFI) Strategic Plan (2017). Available at $<$ nidcap. org/wp- content/uploads/2017/12/2017-Strategic-Plan-Adopted-Oct2017-minor-edits-Nov-2017.pdf>
2. Silberstein D and Tyebkhan JM. Summary Document 'Topic 3 - Training Materials and Methodologies; Summary and Action items from NIDCAP Trainers Meeting 2019'. Available on request from J Tyebkhan

3. Specialty neonatal training offered in Edmonton includes Mindfulness in the NICU and Targeted Neonatal Echocardiography

4. Ghoman SK, Cutumisu M, Schmölzer GM. Simulation-based summative assessment of neonatal resuscitation providers using the RETAIN serious board game-a pilot study. Front Pediatr 2020 Jan 31;8:14. doi: 10.3389/fped.2020.00014. eCollection 2020

5. Sonnenberg L, von Hauff P, Lemieux L. Electronic portfolios for assessment in postgraduate medical education. Med Ed Publish, 2017. Available at https://doi.org/10.15694/ mep.2017.000066

6. Larson C et al. See https://edmontonjournal.com/news/local-news/heart-transplantmodel-takes-star- wars-shape 